\title{
Database Click Stream of E-commerce Functional
}

\author{
Evi Triandini ${ }^{1}$, Septiyawan Rosetya W $^{2}$, I Gede Suardika ${ }^{3}$, I Ketut Putu Suniantara ${ }^{3}$ \\ 1,3,4 4Institut Teknologi dan Bisnis STIKOM Bali, Indonesia \\ ${ }^{2} 2$ Institut Teknologi Adhi Tama Surabaya, Indonesia
}

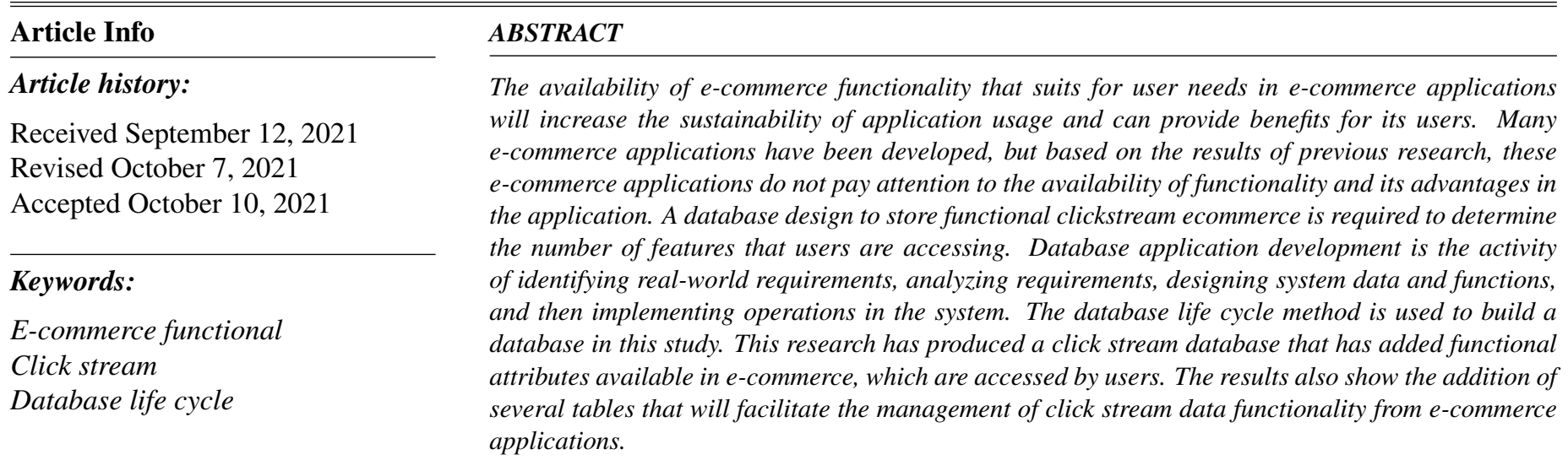

\section{Corresponding Author:}

Evi Triandini,

Department of Information Systems,

Institut Teknologi dan Bisnis STIKOM Bali.

Email: evi@stikom-bali.ac.id 


\section{INTRODUCTION}

E-commerce can provide different opportunities for Small and Mediums Enterprises (SMEs) and help SMEs deal with the use of information technology [1]. Furthermore Ergun Gide added that e-commerce has an importance role for SMEs because ecommerce provides a good opportunity for SMEs to be able to compete in the global market [2]. Rianto et al. [3] shows that the adoption of information technology (IT) in SMEs has an impact on increasing the competitiveness of nation through increased productivity and speed of responding to demand an market expandion. Therefore, the use of e-commerce allows SMEs to improve efficiency and competitive position in the global market [4].

E-commerce is the process of buying, selling, transferring or exchanging goods, services and / or information over computer networks (including the Internet) [5]. E-commerce is classified based on transsactions or relationships between participants. This research uses Business-to-Consumer (B2C) type. B2C is an e-commerce model where business people sell goods or services to individuals. B2C uses many ways to approach consumes, including the mechanism of an online shop such as electronic shopping mall or it can also use portal concept. E-commerce provides companies with advantages by improving efficiency, reducing storage costs, increasing sales, increasing customer relationships, opening up new markets, and ultimately obtaining financial returns [6-10]. E-commerce provides SMEs with a cheap way to promote themselves, introduce new products to the market, improve communication, obtain information and identify potential competitive partners [11]. The adoption of e-commerce in this research is defined as the decision to use e-commerce to conduct business or transactions with customers.

Software requirements provide the appropriate mechanism for understanding what is needed by consumers or users. Functional needs can be satisfied into two, namely functional requirements or service owned by the system and non-functional requirements that explain the properties and constrains of the systems [12]. Functionality describes the services, features and functions available to the systems to users. While non-functionality explains the constraints, characteristics and properties of the systems both in development and in the operating environment [13]. According [14], key elements that are important for developing websites must pay attention to stages of determining software requirements. The functional requirements used in this study are results of previous research namely mapping the functional needs of e-commerce [15]. The availability and priority of functional needs in e-commerce applications developed refers to the mapping of previous research.

An e-commerce page has developed where interactive two-way to support the buying and selling transaction process is available. E-commerce pages are not only for conducting online trading activities, but they are also used to manage e-business process [16]. The surfing behavior of the user shows his actual interest in the products of the e-commerce website. With the development of e-commerce, user-specific orientation and purchasing behavior can be fully preserved [17]. The surfing behavior of the user shows his actual interest in the products of the e-commerce website. With the development of e-commerce, user-specific orientation and purchasing behavior can be fully preserved [17]. Clickstream data can often be used in online shopping websites. Such data typically includes information about individual consumer clicks and purchases [18]. The functional needs of e-commerce that are suitable for users and available in e-commerce applications will increase the continued use of the application. The functional requirements of software will provide more appropriate mechanisms to understand what is needed by the user. User activities that access functionalities available in e-commerce need to be properly recorded and managed. Managing information applying a database permits us to become strategic users of the data we have [19].

A current click is the recording of client taps while examining the site or use of other programming applications. When the customer, click any point on the website page, the task is recorded within the web server or client [18], [20-24]. The analysis of data transmission data is valuable for searching for web movement, statistical topography, programming tests and to dissect representative profitability. Based on the click click information or the adjustment module, it must be collected from server registration documents [21]. The main purpose of the click sign is to understand customer behavior and provide administrators with the understanding of the website of what guests do on their website. The information can be used for several reasons, for marketing. You can use current current analysis to improve consumer loyalty with the company's website. This can produce a business advantage, used to examine the profitability of the promotion of a company page or site.

A database is a public collection of related data used to support a specific organization's behavior. A database management system (DBMS) is a set of programs that enables users to set up, manage, and control all access to the database. The main goal of a DBMS is to provide an environment that is both user-friendly and capable of retrieving and storing information. Database application development is the process of discovering real requirements, analyzing requirements, designing system data and functions, and then implementing operations in the system [19]. The database life cycle is a method of developing a database model. The life cycle of the database system is a suitable and valuable framework for considering the development of the database system. The framework provides a structured background for database administration functions. The collection of user requirements and the design of the database is done during the development phase. The activities occurring in the life cycle can be further differentiated from the point of view of the designer / user [25]. The fundamental goal of database design is to facilitate users to get the exact data they need

Matrik: Jurnal Managemen,Teknik Informatika, dan Rekayasa Komputer,

Vol. 21, No. 1, November 2021: $75-86$ 
to accomplish their duties within the organization and distribute that data in a timely manner. The elements in the database meet the complete data requirements of the user organization based on its overall goals, internal organizational structure, and access to project data. The database structure produced by the database design process enables data to be accessed quickly enough so that those who need the data can effectively complete their work. The application development phase includes three steps: 1) requirement formulation and analysis, 2) logical design, and 3) physical design [19].Requirements phase is the most important phase, because the majority of subsequent design decisions are based on it. The main task is gathering information content and managing requirements from all of the identified and prospective users of the database. Analysis of the requirements guarantees the consistency of users objectives, as well as the consistency of their view of the organizations information flow. Logical database design attend to the design and refinement of an information structure through the consolidation of the user requirements specifications. The result of the logical design is a database definition or schema. The physical design involves the design of the equivalent of the internal schema. The logical schema will be indicated by SQL data definition language (DDL) statements, which explain the database that needs to be implemented to meet the user requirement. The requirements phase is the most important phase because most subsequent design decisions are based on it. The main task is to accumulate information content and processing requirements from all identified and potential users of the database. The needs analysis ensures the consistency of users' goals and their views on the flow of information in the organization. Logical database design solves the design and improvement of the information structure by integrating user requirements and specifications. The result of the logical design is the database definition or schema. The physical design includes the design that matches the internal pattern. The logical mode is indicated by SQL Data Definition Language (DDL) statements that describe the database that must be implemented to meet user requirements [19].

Several previous studies have used a life cycle database to develop a database. The results of Arif and Hendra [26] show that the use of the life cycle database method can form a database for PT FTs standard operating procedures using Oracle. The database that has been created is also able to interact with other tables that have been related and with tables that have been created previously by company. Other research results also show that the use of the life cycle database method produces a database design that support data integrity of each related table and facilitates the implementation by the programmer [27-29]. The method I use in this research is the one that has been used by some previous researchers. Their research results showed that it is worthy of my research.

Based on the description of the problem and the reference of several previous studies, a research question of this study is how to provide a functional e-commerce click stream database? The purpose of the research in this article is the development of a functional access log database to store user access to functional requirements available in e-commerce. The availability of functional e-commerce needs that are widely accessed by users is used to develop e-commerce that is appropriate for the characteristics of SMEs. The contribution of this research is to provide a table or attribute in a database that will be built to store clickstream customers who access functionally available e-commerce applications.

The click stream of e-commerce functional is described in the next sections according to the following structuring: Section 2. describes the method of research that is explain how to analyze and develop database; Section 3. describes the functional requirements and local schema of the database as a result of this research; Section 4. brings some conclusions.

\section{RESEARCH METHOD}

This stage explains the timing of the research, including research design, research methods (in algorithms, pseudocode, or other forms), how to test, and how to collect data [1-3]. This study uses a database life cycle method to build a clickstream database of functional e-commerce needs. The method used in this study can be seen in Figure 1. The construction of a clickstream database begins with the e-commerce database that was built in previous studies. The next steps are understanding the systems that will be created by collection data and functional requirements of previous studies. Some functional requirements have the same character, then the access data can be stored in one table. Based on the statemen of data requirements, a conceptual data model will be created.

Conceptual data models relate to the implication and construction of the data, but not to the details of their likely implementation. Database design begins with a conceptual data model and generates a specification of the logical schema that defines the specific type of database system required. The detailed relationship specification is the result of this stage. A logical model that meets all of the tables and constraints required to describe data in the conceptual data model. Realize the structure of a database that contains a logical model that you can specify. Implementation will include matching design requirements with the best implementation tools available [19]. 


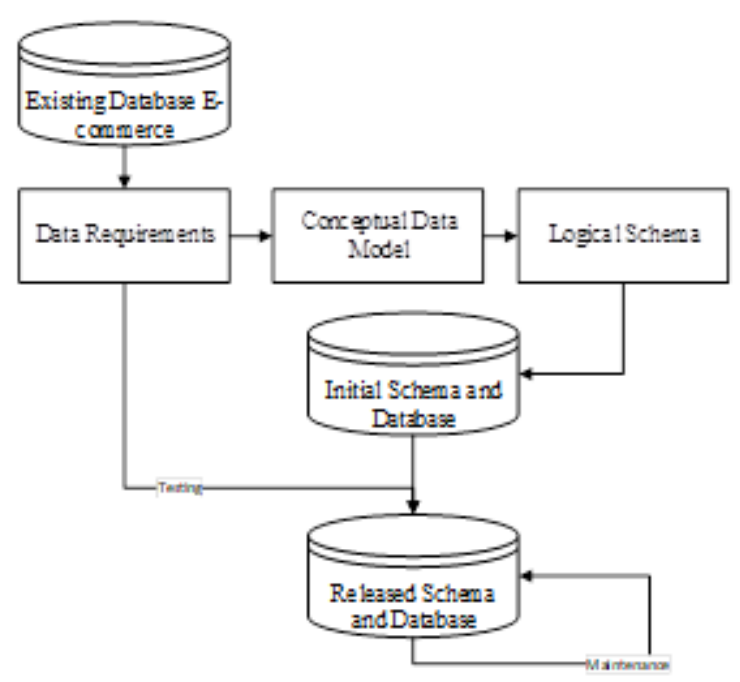

Figure 1. Database Design Approach

\section{RESULT AND ANALYSIS}

\subsection{Data Requirements}

Research builds a database that stores clickstream functional requirements available on e-commerce. The functional requirements of e-commerce used in the study are shown in the Table 1.

Table 1. Functional Requirements

\begin{tabular}{llll}
\hline Code & Functional requirement & Code & Functional requirement Eerdagangan Elektronik \\
\hline F3 & Product Comparation & F31 & Registration \\
F5 & Stock Availability & F32 & Tax payment estimation \\
F6 & Product category & F33 & Cost shipping estimation \\
F7 & Sorting of Product & F34 & Shopping Chart \\
F8 & Product discount & F36 & Create Multi Invoice \\
F10 & Product promotion (price) Potongan Harga & F37 & Refund process \\
F11 & Product promotion (Percentage) & F38 & Invoice printing \\
F12 & New Product promotion & F39 & Print Packing slip \\
F13 & Send page to friend & F40 & Cash on Delivery (COD) \\
F14 & Promotion with banner & F41 & Payment through bank \\
F15 & Like at Sosial Network & F42 & Payment using credit card \\
F16 & Live Chat & F43 & Real-time shipping cost \\
F18 & Advance Searching & F44 & Cost table based on weight \\
F19 & Search Engine Friendly & F45 & Cost table based on volume \\
F24 & On-line Status & F46 & Dashboard for consumer \\
F25 & Consumer order history & F47 & Dashboard for Low level manajement \\
F26 & New Product order & F48 & Dashboard for Middle manajement \\
F27 & Address book for shipment & F49 & Dashboard for Top level manajement \\
F28 & News subscription & F50 & Multi Language \\
F29 & Product review & F51 & Multi currencies \\
F30 & Real-time shipping & & \\
\hline
\end{tabular}

Matrik: Jurnal Managemen,Teknik Informatika, dan Rekayasa Komputer,

Vol. 21, No. 1, November 2021: 75 - 86 


\subsection{Conceptuaal Data Model}

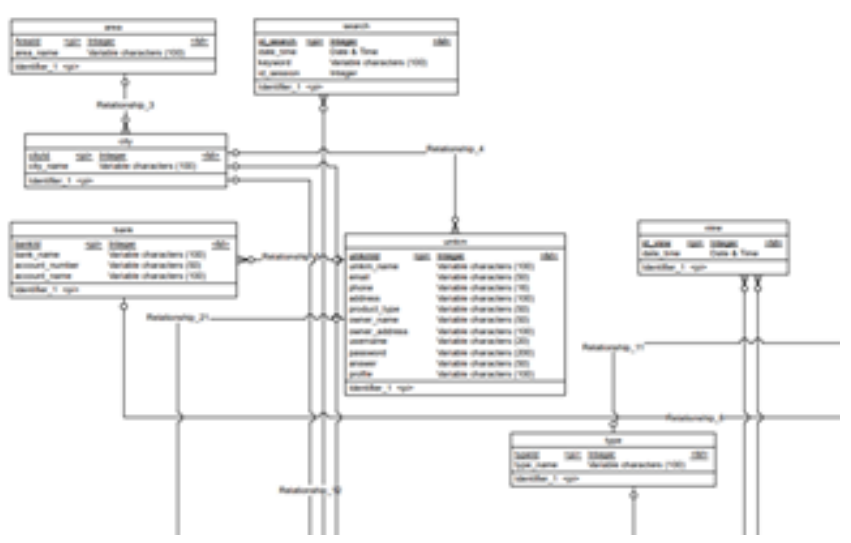

Figure 2. Part of CDM

The number of entities that have been identified in this research database design is 29. This article only shows a part of the CDM design (Figure 2). While the description of each entity can be seen in the following description.

\subsection{Logical Schema}

Based on these functional requirements, clickstream functional e-commerce has been created in the database. The addition of tables and attributes for storing clickstream has been adjusted to the availability of functional e-commerce. The following describes the Logical database design storing clickstream:

\section{Functionality for F10, F11, F12 and F14}

Functional F10 to F14 is functional to promote the existence of a product or company profile. The entity table promotion_type is built to store clickstream types of promotions such as discounted price promotions, discounted percentages, and new products. Clickstream promotion functionality is placed on the front page of the website in the form of a slider. The logical design of promotional type functionalities is shown in the figure 3 .

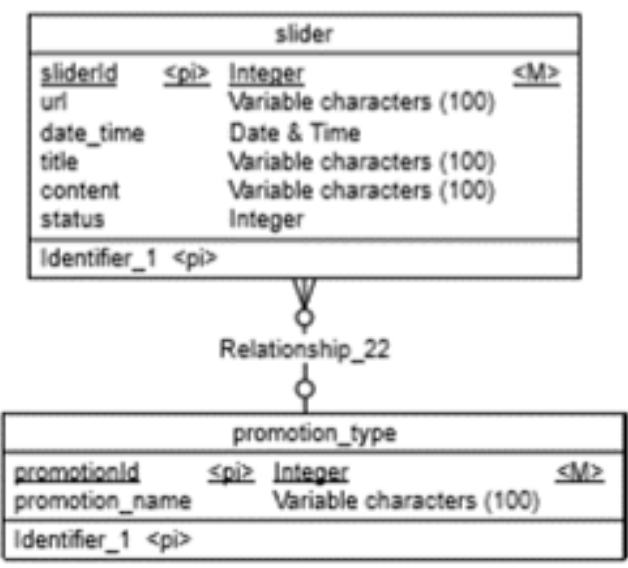

Figure 3. Promotion Type Functionality 


\section{Functionality for $\mathbf{F 3}$}

F3 functionality is a product comparison functional. The functional clickstream will be stored in the product comparison_entity. Users can compare more than 2 products and are automatically recorded by the system. Figure 4 shows table of product comparison functionality.

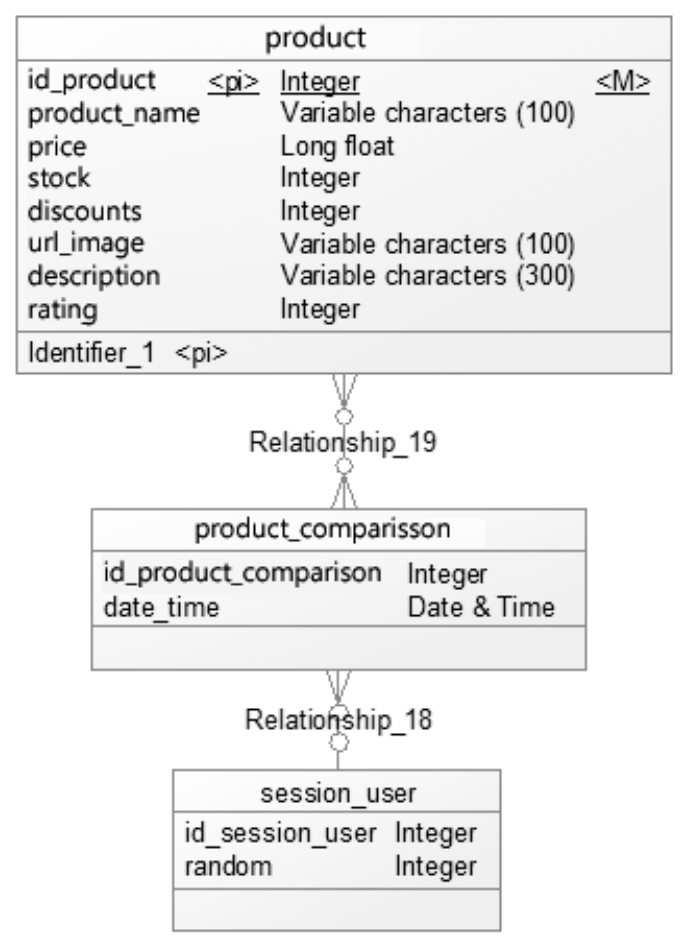

Figure 4. Product Comparison Functionality

\section{Functionality for F3, F6, F7 and F8}

The F3, F6, F7 and F8 functionalities are product-related functionalities. The functionality includes the availability of products, categories, sorting and product price discounts. Category and product entities will store clickstream users for this functionality. Figure 5 shows product functionality.

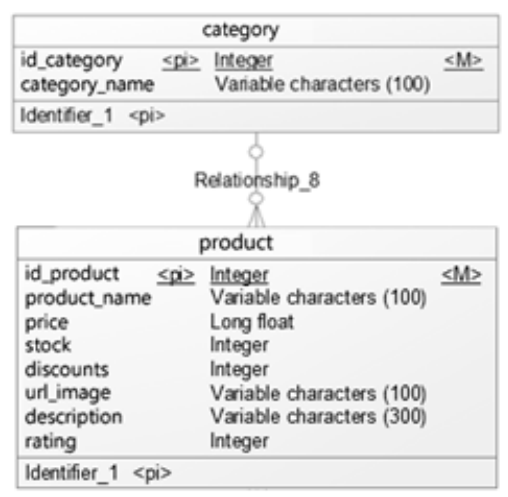

Figure 5. Product Functionality

Matrik: Jurnal Managemen,Teknik Informatika, dan Rekayasa Komputer,

Vol. 21, No. 1, November 2021: 75 - 86 


\section{Functionality for F24, F27, F28, dan F29}

F24, F27, F28 and F29 functionality are functionalities related to product reviews provided by consumers. The logic product review design is shown in Fig. Each customer can review many products, but each product can be reviewed by many customers. In addition, the customer entity also facilitates the clickstream of the F24, F27 and F28 functions to store the login, subscribe and address status as a reference for the online status, subscribe and address book functions. Figure 6 shows product review functionality.

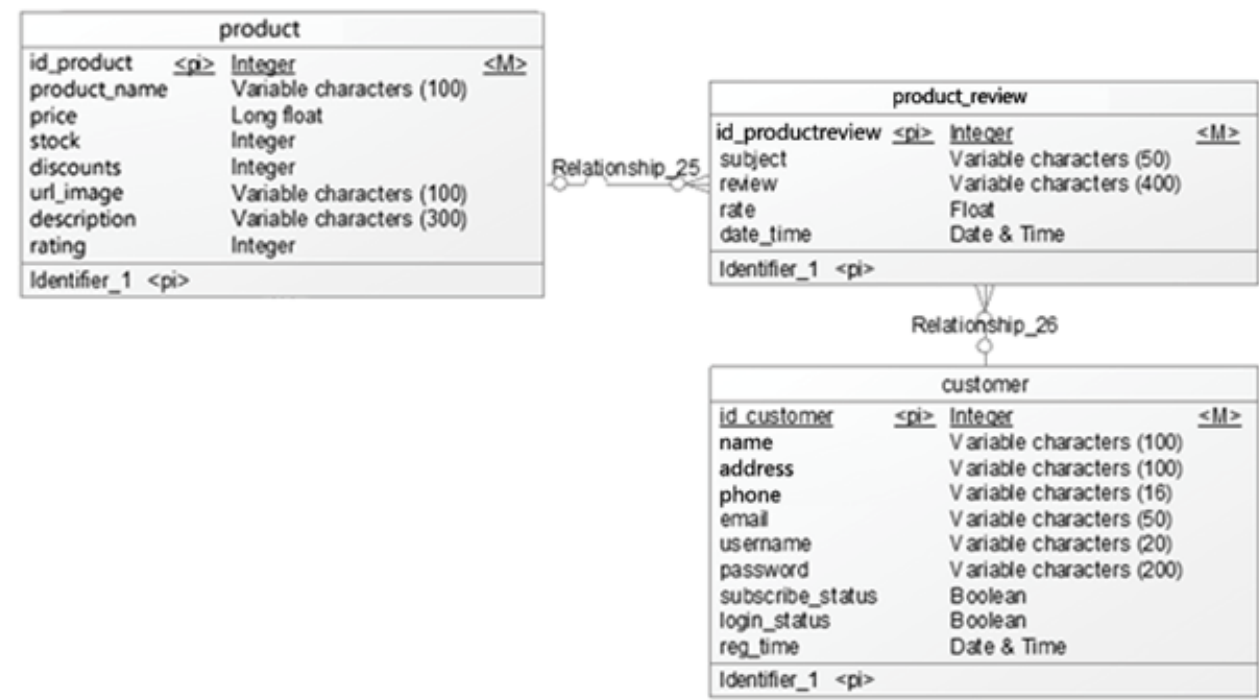

Figure 6. Product Review Functionality

\section{Functionality for F50 and F51}

Multi language and multi-currency are important features for e-commerce, especially e-commerce that has an international market. Therefore, in this system an entity is created to store the Language and currency settings. The settings of the two functionalities are shown in Figure 7.

\begin{tabular}{|c|c|c|}
\hline \multicolumn{3}{|c|}{ setting } \\
\hline id setting & $\leq p i\rangle$ & Integer $\leq M\rangle$ \\
\hline currency & & Integer \\
\hline language & & Integer \\
\hline
\end{tabular}

\begin{tabular}{|c|c|c|}
\hline \multicolumn{3}{|c|}{ language } \\
\hline id_language $\leq p i\rangle$ & Integer & $\leq M\rangle$ \\
\hline language_name & Variable characters $(100)$ & \\
\hline language_code & Variable characters ( 8 ) & \\
\hline
\end{tabular}

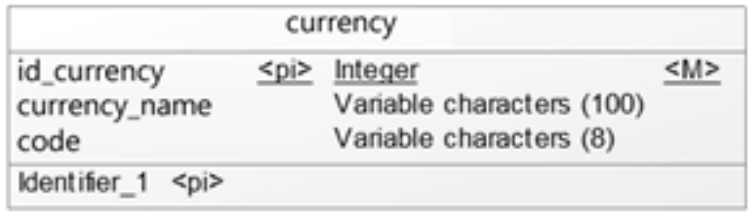

Figure 7. Multi-Currency and Multi Language Functionality 


\section{Functionality for F25 and F26}

The F25 and F26 functionality is a function to manage the history of consumer orders and the latest product orders. The two function stream clicks will be stored in the checkout entity, which is to simplify the ordered product entity stored in the json cart. In order to find out the latest product orders can be seen in the date_time field on the product entity. Figure 8 shows history and product order functionality.

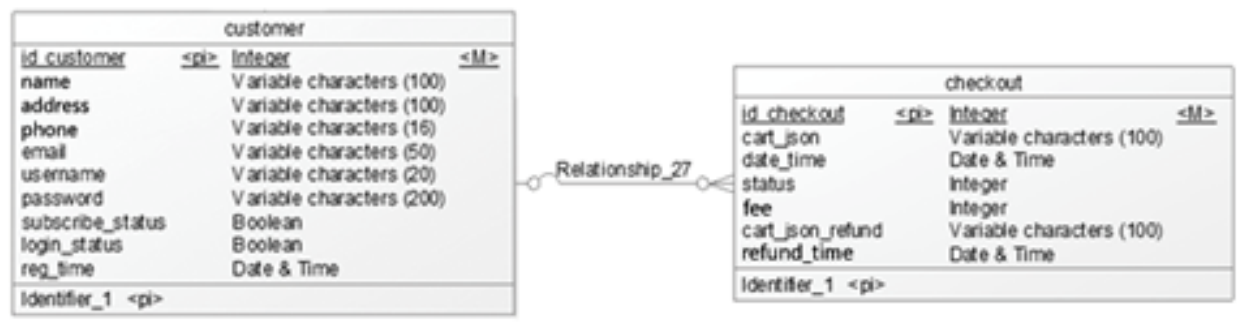

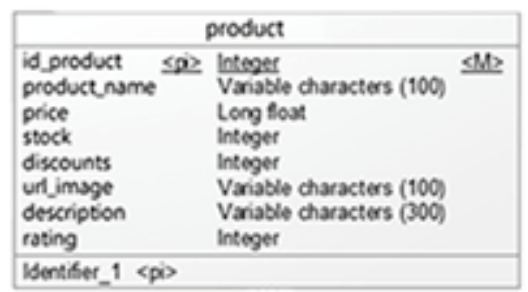

Figure 8. History and Product Order Functionality

\section{Functionality for F34}

The F34 functionality is a function of storing consumer orders. This function is the most important function to see the pattern of customers, especially those who have not logged in or just guest. Therefore, each user adding a product to the cart will be stored in the above entities. Storage functionality is shown in Fig 9.

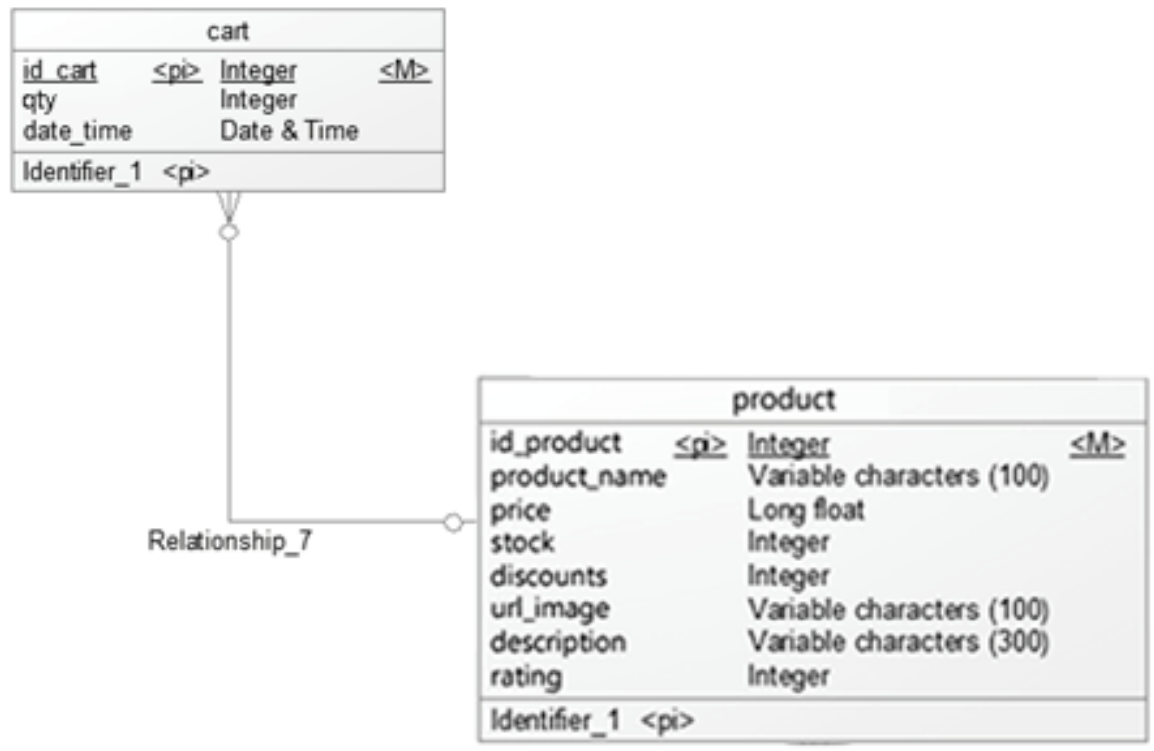

Figure 9. Product Order Functionality

Matrik: Jurnal Managemen,Teknik Informatika, dan Rekayasa Komputer,

Vol. 21, No. 1, November 2021: 75 - 86 


\section{Functionality for F31}

The registration function usually exists in e-commerce applications. This function is useful for storing consumer data. This data will be used to simplify the process of sending products ordered by the user. Customer registration function entities are shown in Figure 10.

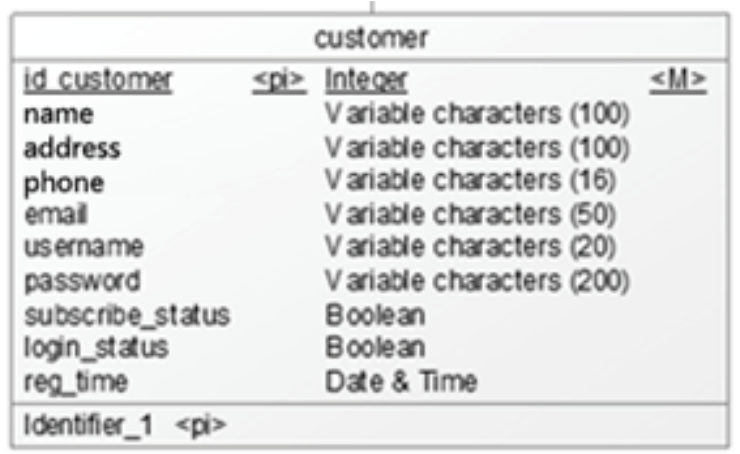

Figure 10. Registration Functionality

\section{Functionality for F36 up to F40}

Functions $\mathrm{f} 36$ to F40 are functions that are used to manage the process of ordering goods completed by consumers. The entity used to facilitate the invoice printing and slip packing functions is in the checkout and shipping address entities. While entities that facilitate cash on delivery and other shipping services are stored in a shipping type entity. The refund process will also be stored at the checkout entity. The functionality shown in Figure 11.

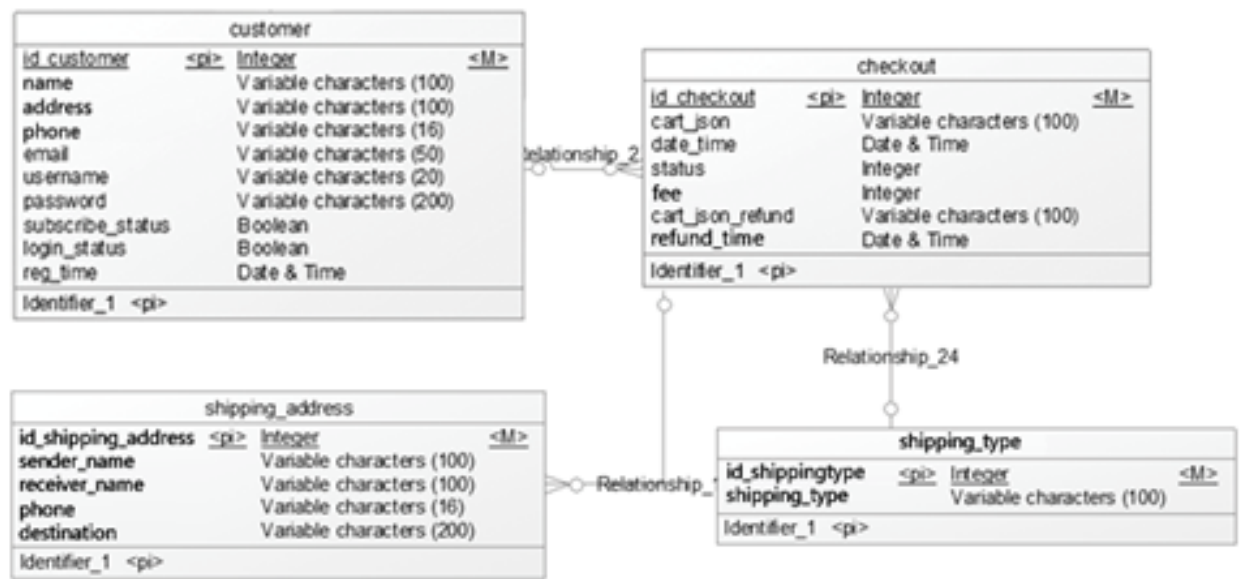

Figure 11. Shipping functionality

\section{Functionality for $\mathbf{F} 41$}

F41 functionality is a function of payment of booking transactions through transfers to local banks. Collaboration with local banks will be carried out with a system of collaboration with sharing APIs between systems developed with a bank system, so that checking for payments is not necessary to be done manually anymore and the system validates automatically. 


\section{Fungsionality for F46, F47, F48 and F49}

F46 to F49 functions are common functions in an e-commerce in the form of a dashboard. Dashboard is a function that contains all information regarding company profiles, products, consumers, product orders, payments, shipping and income reports. All entities in the database designed in this study have been developed to support these 4 functionalities.

\section{Functionality :F13, F15, F16, F18, F19, F30, F33 and F43}

The 8 functional types will be developed using APIs from other developers, such as www.addthis.com, dashboard.zopim.com, etc. The research has resulted in a clickstream functional requirements database contained in e-commerce applications. Users who access functional requirements that are available in e-commerce will be stored in data that has been available in the database. Clickstream database which refers to the e-commerce database that has been developed previously is expected to be used to evaluate the usefulness and usefulness of e-commerce for its users. The use of the life cycle database method in this study is in accordance with the work of research that has been carried out by [25].

The result of this research is a database design that has data to store click stream data from users. The results of this study are expected to provide benefits for database owners to complete organizational tasks and distribute the data at the right time. This is in accordance with the results of research by [17], [18], [21], [22], [30-32]. User click stream data storage on the website is needed to understand customer behavior and provide understanding to website administrators about what guests do on their website. This information can be used to develop marketing strategies. The resulting data can later be analyzed to determine consumer behavior and can also be used to increase consumer loyalty to the company. User click stream data will provide business benefits for the company. The data is used to test the profitability of the company's page or website promotion.

\section{CONCLUSION}

Development of a functional e-commerce click-stream database has been made. User activities accessing e-commerce applications can be tracked through the log access. The result of this research can be used to support decision making for e-commerce sites. E-commerce web sites every day can collect a lot of data access. The availability of click-stream data is expected to obtain various types of user behavior patterns can be described to find out the interests and needs of users. The results of this study can be continued by implementing and testing on SMEs.

\section{REFERENCES}

[1] N. Al-Qirim, "The Adoption of E-Commerce Communications and Applications Technologies in Small Businesses in New Zealand," Electronic Commerce Research and Applications, vol. 6, pp. 462-473, 2007.

[2] E. Gide, "The Key Strategies for E-Commerce Success Service SMEs in China", IEEE hal 229 -234," in IEEE International Conference on Service Operations and Logistics, and Informatics, Shanghai, 2006, pp. 229-234.

[3] Y. Rianto, E. Aminullah, C. Laksani, D. Prihadyanti, B. Triyono, and L. Handoko, Peta dan Strategi Adopsi Teknologi Informasi di UKM Manufaktur. Jakarta: LIPI Press, 2007.

[4] L.-M. Chang, S.-I. Chang, C.-T. Ho, D. Yen, and M.-C. Chiang, "Effects of IS Characteristics on The E-Business Success Factors for Small-and Medium-Sized Enterprises," Computers in Human Behavior, vol. 27, pp. 2129-2140, 2011.

[5] E. Turban, Introduction to Electronic Commerce, 2nd ed. New Jersey: Pearson Prentice Hall, 2009.

[6] E. Triandini, A. Djunaidy, and D. Siahaan, "Determining E-Commerce Adoption Level by SMEs in Indonesia Based on Customer-Oriented Benefits," in Internatioal Conference on Information Technology, Computer and Electrical Engineering (ICITACEE2014). Diponegoro University: IEEE, nov 2014, pp. 281-285.

[7] F. Wahid and L. Iswari, "Information Technology Adoption by Small and Medium Enterprises in Indonesia," in The National Seminar on Information Technology Application, Yogyakarta, 2007, pp. 75-79.

[8] E. Triandini, A. Djunaidy, and D. Siahaan, "Development of A Conceptual Model of E-Commerce Adoption for SMEs in Indonesia," in 2013 International Conference on Information Technology and Electrical Engineering (ICITEE). Departement of Electrical Engineering and Information Technology: IEEE, 2013, pp. 93-96. 
[9] G. D. Gregory, L. V. Ngo, and M. Karavdic, "Developing E-Commerce Marketing Capabilities and Efficiencies for Enhanced Performance in Business-to-Business Export Ventures," Industrial Marketing Management, vol. 78, pp. 146-157, 2019.

[10] S. Chong, "Success in Electronic Commerce Implementation: A Cross Country Study of Small and Medium-Sized Enterprises," Journal of Enterprise Information Management, vol. 21, no. 5, pp. 468-492, 2008.

[11] J. Bao and X. Sun, "A Conceptual Model of Factors Affecting E-Commerce Adoption by SMEs in China," in 2010 Fourth International Conference on Management of e-Commerce and e-Government (ICMeCG), oct 2010, pp. 172 -175.

[12] J. Wiegers, Karl; Beatty, Software Requirements, 3rd ed. Microsoft Press, 2013.

[13] D. Siahaan, Requirements Analysis in Software Engineering, Andi Dewibertha Hardjono, Ed. Yogyakarta: Andi Offset, 2012.

[14] V. S. Moertini, S. Heriyanto, and C. D. Nugroho, "Requirement Analysis Method of E-Commerce Websites Development for Small - Medium Enterprises , Case Study : Indonesia," International Journal of Software Engineering \& Applications (IJSEA), vol. 5, no. 2, pp. 11-28, 2014.

[15] E. Triandini, F. A. Hermawati, and I. K. P. Suniantara, "Hierarchical Clustering for Functionalitites E-Commerce Adoption," Kursor, vol. 10, no. 3, pp. 111-118, 2020.

[16] S.-C. Chu, L. Leung, Y. Hui, and W. Cheung, "Evolution of E-Commerce Web Sites: A Conceptual Framework and A Longitudinal Study," Information \& Management, vol. 44, pp. 154-164, 2007.

[17] L. Chen and Q. Su, "Discovering User's Interest at E-Commerce Site Using Clickstream Data," 2013 10th International Conference on Service Systems and Service Management - Proceedings of ICSSSM 2013, pp. 124-129, 2013.

[18] Y. Chen and S. Yao, "Sequential Search with Renement Model and Application with Click-Stream Data.pdf," Management Science, Articles in Advance, pp. 1-22, 2016.

[19] A. Watt and N. Eng, Database Design - 2nd Edition. Victoria: B.C.: BCcampus, 2014.

[20] G. Wang, X. Zhang, S. Tang, H. Zheng, and B. Y. Zhao, "Unsupervised Clickstream Clustering for User Behavior Analysis," Conference on Human Factors in Computing Systems - Proceedings, pp. 225-236, 2016.

[21] R. Hanamanthrao and S. Thejaswini, "Real-Time Clickstream Data Analytics and Visualization," RTEICT 2017 - 2nd IEEE International Conference on Recent Trends in Electronics, Information and Communication Technology, Proceedings, vol. 2018-Janua, pp. 2139-2144, 2017.

[22] M. Scholz, "R Package Clickstream: Analyzing Clickstream Data with Markov Chains," Journal of Statistical Software, vol. 74, no. $4,2016$.

[23] C. Lakshminarayan, R. Kosuru, and M. Hsu, “Modeling Complex Clickstream Data by Stochastic Models,” pp. 879-884, 2016.

[24] D. Schellong, J. Kemper, and M. Brettel, "Generating Consumer Insights From Big Data Clickstream Information and The Link with Transaction-Related Shopping Behavior," Proceedings of the 25th European Conference on Information Systems, ECIS 2017, vol. 2017, 2017.

[25] T. J. Teorey and J. P. Fry, “The Logical Record Access Approach to Database Design,” ACM Comput. Surv., vol. 12, no. 4, 1980.

[26] S. M. Arif, H. Purwoko, T. Barat, and J. Selatan, "Perancangan Basis Data Oracle Standar Operasional Prosedur," in Seminar Nasional Riset dan Teknologi (SEMNAS RISTEK). Jakarta: Universitas Indraprasta PGRI, 2020, pp. 43-46.

[27] Nofiyani, "Model Basis Data untuk Mendukung Sistem Administrasi Pelayanan dan Perbaikan Motor," in Simposium Nasional Ilmiah, no. November. Jakarta: Fakultas Teknologi Informasi, Universitas Budi Luhur, 2019, pp. 367-375.

[28] F. S. Handayani and M. P. Putri, "Desain Database dan Hypertext untuk Website Penelusuran Minat Peserta Didik sebagai Layanan Bimbingan Konseling," in Seminar Nasional Sains dan Teknologi (SNST) ke-8, vol. 2, no. 2014. Semarang: Fakultas Teknik Universitas Wahid Hasyim, 2017, pp. 13-18. 
[29] W. S. Prasetya, "Perancangan Model Basis Data Relasional dengan Metode Database Life Cycle," in Seminar Nasional Informatika 2015. Medan: Universitas Potensi Utama, 2015, pp. 91-98.

[30] T. Huang and J. A. Van Mieghem, "Clickstream Data and Inventory Management: Model and Empirical Analysis," Production and Operations Management, vol. 23, no. 3, pp. 333-347, 2014.

[31] S. Bansal, C. Gupta, and A. Sinha, "Clickstream \& Behavioral Analysis with Context Awareness for E-Commercial Applications," 2017 10th International Conference on Contemporary Computing, IC3 2017, vol. 2018-Janua, no. August, pp. 1-6, 2018.

[32] Y. S. Kim and B. J. Yum, "Recommender System Based on Click Stream Data Using Association Rule Mining," Expert Systems with Applications, vol. 38, no. 10, pp. 13 320-13 327, 2011. 